Shu-Yu Lin

Wei-Hsi Chen

Chuen-Ying Liu

Department of Chemistry,

National Taiwan University,

Taipei, Taiwan

\section{Nucleoside monophosphates recognition using macrocyclic polyamine bonded phase in capillary electrochromatography}

\begin{abstract}
An open-tubular wall-coated macrocyclic polyamine capillary column $(70 \mathrm{~cm} \times 75 \mu \mathrm{m}$ ID) with $50 \mathrm{~cm}$ effective length for the separation of nucleoside monophosphates is described. Some parameters with respect to concentration, $\mathrm{pH}$, composition of the buffer, and voltage in order to optimize the separation were studied. The coated capillary showed reversed electroosmotic flow (EOF), allowing anions to be separated in the co-EOF mode. Baseline separations were achieved for the eight nucleotides in less than 26 min using a background electrolyte consisting of $\mathrm{H}_{3} \mathrm{PO}_{4}-\mathrm{NaH}_{2} \mathrm{PO}_{4}(30 \mathrm{~mm}$, $\mathrm{pH}$ 3.10), an applied voltage of $-15 \mathrm{kV}$, and detection at $254 \mathrm{~nm}$. The macrocyclic polyamine on the capillary wall introduced anion coordination for the interaction with the analytes, the strength of which could be moderated by the type and concentration of the competing ion used in the background electrolyte (BGE). With a low concentration of the competing ion (phosphate ion), the migration behavior followed that obtained in the electrophoretic system. Increasing the concentration of the competing ion resulted in a faster migration and more complete elution of the analyte. The method established was also employed for the analysis of nucleotides in mushrooms. Aqueous extracts of mushrooms from different species and various extraction methods were injected directly for the analysis. Uridine 5'-monophosphate, guanosine 5'-monophosphate, adenosine 5'-monophosphate, and cytidine 5'-monophosphate, were found in the sample tested.
\end{abstract}

Keywords: Bonded phase / Capillary electrochromatography / Macrocyclic polyamine / Nucleoside monophosphate

EL 4777

\section{Introduction}

Anion coordination and molecular recognition of anionic substrates have been studied much less than cation complexation despite the very important role played by negatively charged species in chemistry and biology. The complex between a protonated azacrown and ATP, described by Lehn et al. [1] is a most impressive example of what can be achieved by matching of many ionic sites in host and guest molecules. However, only phosphates and not nucleosides themselves are involved in the binding processes [2]. Associations between host and guest molecules are usually necessary for several binding sites. This is evident because noncovalent interactions are usually weak, and concerted interplay between many sites is the only way to achieve strong and specific complexation

Correspondence: Professor Chuen-Ying Liu, Department of Chemistry, National Taiwan University, 1, Sec. 4, Roosevelt Road, Taipei, 10617, Taiwan

E-mail: cyliu@ccms.ntu.edu.tw

Fax: $+886-2-23638543$

Abbreviation: [28]ane- $\mathbf{N}_{6} \mathbf{O}_{2}, 4,8,12,18,22,26$-hexaaza-1,15-dioxacyclooctaeicosane (recognition) of a guest molecule. In other words, complexation will be most efficient when the shapes and arrangements of binding sites in host and guest molecules fit each other [3].

Nucleotides, nucleosides, and bases are essential constituents of nucleic acids and enzyme cofactors required for the proper functioning of cells, tissues, and organs. The separation and detection of these compounds is an interesting and challenging topic. The analysis of nucleosides and nucleotides has in most cases been performed by high-performance liquid chromatography (HPLC) using either reversed-phase HPLC with gradient elution or reversed-phase ion-pairing chromatography [4-11]. Electrophoresis is the major separation method in molecular biology. For the last decade, there have been a number of reports of successful studies on the separation of nucleotides by capillary electrophoresis (CE). CE has been proven to have several advantages over HPLC, particularly in terms of its high efficiency and small volume requirements. Here, we only studied those for the separation of nucleoside monophosphates [12-31]. Among them, a number of studies involved the addition of quaternary ammonium salt as EOF modifier [12, 25, 27, 29, $30]$, cyclodextrin $[15,23]$, acetonitrile $[20,22]$, mixture of 
cyclodextrin and $\mathrm{MgCl}_{2}$ [23], or metal ions [23, 25, 27, 30] in the background electrolyte (BGE). Examples also included micellar electrokinetic chromatography (MEKC) $[23,24]$, the use of cross-linked polyacrylamide [13], polyethylene oxide [26], diol-bonded [28], and Ucon-coated columns $[14,16,18,22]$, or medium at $\mathrm{pH}$ above 10 [19, $21,31]$ to achieve a better separation.

Capillary electrochromatography (CEC) is in many ways comparable to HPLC, but CEC is theoretically able to provide better separations, due to the higher efficiency caused by the plug-like flow which is to be compared to the more parabolic flow observed in HPLC. The stationary phase may be either bonded to the walls of the capillary (open-tubular CEC) or packed small particles $(<5 \mu \mathrm{m})$ in the capillary (packed CEC). Recently, Sykora et al. [32] reported the separation of oligonucleotides on novel monolithic columns with ion-exchange functional surfaces. Our previous reports have demonstrated the preparation and evaluation of the macrocyclic polyaminebonded phase for the separation of organic anions, inorganic anions, and metal speciation [33-36]. Separation of nucleotides from complex mixtures requires high selectivity of the chromatographic method and is desired to be doable within a short time, especially with a view to methods suitable for clinical diagnostics. Following our success in the separation of small molecules, we anticipated that this novel column would be well suited for the separation of nucleotides.

\section{Materials and methods}

\subsection{Apparatus}

A high-voltage power supply with a $30 \mathrm{kV}$ capacity (Model 890-CE, Jasco, Tokyo, Japan) and a variable-wavelength UV/Vis detector (Jasco 870-CE) were employed for CE. Electropherograms were recorded and processed with a PC SISC-Lab data acquisition system (Scientific Information Service Co., Taiwan). The separations were carried out on a fused-silica capillary column with an external coating of polyimide (Resteck, Bellefonte, PA, USA) and chemically modified with $4,8,12,18,22,26$-hexaaza-1,15-dioxacyclooctaeicosane ([28]ane- $\mathrm{N}_{6} \mathrm{O}_{2}$ ), a 28-membered macrocyclic ligand containing oxygen and nitrogen as donor atoms. The modified capillaries were of $75 \mu \mathrm{m}$ ID and the total length of the capillary was $70 \mathrm{~cm}$, with a distance of $50 \mathrm{~cm}$ between the injection end and the detection window.

\subsection{Reagents and chemicals}

Most chemicals were of analytical reagent grade from Merck (Darmstadt, Germany). Purified water (18 M $\Omega \mathrm{cm}$ ) from a Milli-Q water purification system (Millipore, Bed- ford, MA, USA) was used to prepare all solutions. Uridine 5'-monophosphate (5'-UMP), 2'3'-cyclic uridine monophosphate (2'3'-cUMP), guanosine 5'-monophosphatae (5'-GMP), 2'3'-cyclic guanosine monophosphate (2'3'-cGMP), adenosine 5'-monophosphate (5'AMP), 2'3'-cyclic adenosine monophosphate (2'3'cAMP), cytidine 5'-monophosphate (5'-CMP), 2'3'-cyclic cytidine monophosphate (2'3'-cCMP), phosphoric acid, and sodium phosphate were purchased from Sigma (St. Louis, MO, USA). $\gamma$-Glycidoxypropyltrimethoxysilane was obtained from Aldrich (Milwaukee, WI, USA). Citric acid, formic acid, benzyl alcohol and dimethyl formamide were obtained from Merck. All liquid reagents and solvents used in moisture-sensitive reactions were distilled and collected over type $4 \AA$ molecular sieves. Stock solutions $\left(5 \mathrm{mg} \cdot \mathrm{mL}^{-1}\right)$ of the nucleotide were prepared in pure water and diluted appropriately prior to use. All solvents and solutions for CEC analysis were filtered through a $0.45 \mu \mathrm{m}$ cellulose ester membrane (Advantec MFS, Pleasanton, CA, USA).

\subsection{Preparation of open-tubular wall-coated capillary column}

The column was prepared as described in [34]. Prior to any column modifications, fused-silica capillaries $(75 \mu \mathrm{m}$ ID, $70 \mathrm{~cm}$ long) were first flushed with $1 \mathrm{M} \mathrm{NaOH}$ (30 min), then with pure water (15 min), $1 \mathrm{M} \mathrm{HCl}$ (30 min), and pure water (15 $\mathrm{min})$. The capillaries were purged with nitrogen for $20 \mathrm{~min}$, then dried at $110^{\circ} \mathrm{C}$ overnight. For coating, the capillary was filled with a $10 \% \mathrm{w} / \mathrm{v}$ solution of $\gamma$-glycidoxypropyltrimethoxysilane in toluene under pressure of $30 \mathrm{psi}$. The filling rate was about $0.1 \mathrm{~mL} \cdot \mathrm{min}^{-1}$. The capillary was kept for $3 \mathrm{~h}$ at $110^{\circ} \mathrm{C}$ for silylization. After purging with toluene to remove unreacted reagent for several minutes, the capillaries were dried in a vacuum oven. The capillary was then filled with a $1 \% \mathrm{w} / \mathrm{v}$ solution of the macrocyclic compound, [28] ane- $\mathrm{N}_{6} \mathrm{O}_{2} \cdot 6 \mathrm{HCl}$ in $\mathrm{N}, \mathrm{N}$ dimethylformamide. After standing for $10 \mathrm{~h}$ at $120^{\circ} \mathrm{C}$ for functionalization, the dried capillaries were purged with ethanol and pure water for several minutes before equilibration with buffer solution. They were then ready for use.

\subsection{Real samples for method evaluation}

Mushrooms of different species including Japanese Shitake and Taiwanese Shanggu I and II were obtained from the supermarket. They were cut into small pieces (ca. $2 \mathrm{~mm}^{2}$ ) prior to the following steps. Aliquots of the sample (1.5 g in $20 \mathrm{~mL}$ pure water) were prepared in different ways: (i) Following immersion of the sample in pure 
water at ambient temperature (20 min), then heating in a microwave oven (20 s); (ii) heating the sample in a water bath at boiling temperature for $15 \mathrm{~min}$; (iii) immersion of the sample in pure water at ambient temperature for $60 \mathrm{~min}$.

\subsection{CE conditions}

Before analysis, the coated capillaries were preconditioned with running buffer. They were rinsed with buffer between runs, and coupled with $1 \mathrm{~mm} \mathrm{NaOH}$ (1 min) only at the first run of the day. The running buffer and the sample solutions were degassed in an ultrasonic bath for $5 \mathrm{~min}$ prior to use. Samples were introduced electrokinetically at the cathodic end of the capillary column. The appropriate background electrolyte was phosphate buffer. Benzyl alcohol was used as the neutral marker. The analytes were detected by monitoring their absorbance at $254 \mathrm{~nm}$.

\section{Results and discussion}

The $\mathrm{pH}$ of the background electrolyte (BGE) had a significant impact on the protonation of the bonded macrocyclic polyamine (Fig. 1) and the electrophoretic mobilities of the compounds studied. A preliminary test showed that when the sample was injected electrokinetically $(-5 \mathrm{kV}, 10 \mathrm{~s})$ under the condition of the phosphate buffer $(30 \mathrm{~mm}, \mathrm{pH} 4.2)$ and voltage of $-15 \mathrm{kV}$ was applied, only seven peaks were observed for the eight nucleotides, to which 5'-AMP and 2'3'-cCMP were coeluted. 5'-UMP and 2'3'-cGMP were baseline-nonresolved and a broadened peak of 5'-CMP was indicated.

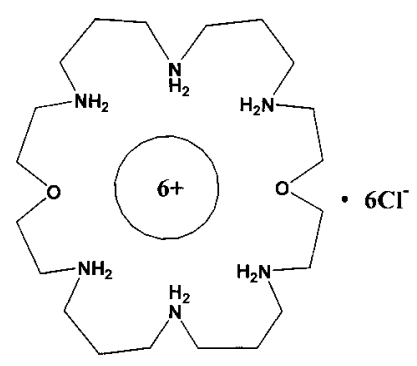

Figure 1. Structure of the macrocyclic polyamine [28]ane- $\mathrm{N}_{6} \mathrm{O}_{2}$ covalently bound to the inner wall of the fusedsilica.

\subsection{Effect of buffer pH}

Nucleosides are relatively weak bases and weak acids. On the other hand, nucleotides are strong acids. At a pH of 2.0, the monophosphates have one negative charge on their phosphate moiety, the diphosphates two, and the triphosphates three. At a pH of 7.0 and above, the nucleotides gain an additional negative charge due to the secondary phosphate dissociation. Table 1 shows the effective charge of the compounds related in this work. It is the sum of the protonated base and phosphate moiety for the nucleotides, therefore, a smaller charge than the abovementioned value would be. As shown in previous studies [34], the [28]ane- $\mathrm{N}_{6} \mathrm{O}_{2}$ bonded phase is fully protonated at $\mathrm{pH}$ lower than 7 . In order to form a sufficiently stable anion complex, phosphate buffer $\left(\mathrm{H}_{3} \mathrm{PO}_{4} / \mathrm{NaH}_{2} \mathrm{PO}_{4}\right)$ at a $\mathrm{pH}$ range of 2-6 was investigated. At $\mathrm{pH} 2.31$ only six peaks were observed, the pair of 2'3'-cAMP $\sim 5$ '-AMP and 2'3'-cCMP $\sim$ 5'-CMP could not be resolved. Increasing the $\mathrm{pH}$ would facilitate the separation. A very good resolution between the mentioned peaks was observed around $\mathrm{pH} 3.10$ (Fig. 2). The migration order was 2'3'cUMP $>$ 5'-UMP > 2'3'-cGMP > 5'-GMP > 2'3'-cAMP $>$ 5'-AMP $>2$ ' ' '-cCMP $>$ 5'-CMP. This is consistent with the effective charge shown in Table 1. Further insight into the complexation property of the bonded phase showed that the larger the formation constant, the slower the mobility of the nucleotide would be.

Table 1. Physical and chemical properties of the nucleotides and other related compounds studied in this work

\begin{tabular}{|c|c|c|c|c|c|c|c|c|c|c|}
\hline \multirow{2}{*}{ Compound } & \multirow{2}{*}{$\mathrm{p} K_{\mathrm{a} 1}$} & \multirow{2}{*}{$\mathrm{p} K_{\mathrm{a} 2}$} & \multirow{2}{*}{$\mathrm{p} K_{\mathrm{a} 3}$} & \multicolumn{7}{|c|}{ Effective charge } \\
\hline & & & & $\mathrm{pH} 2$ & $\mathrm{pH} 3$ & $\mathrm{pH} 4$ & $\mathrm{pH} 5$ & $\mathrm{pH} 6$ & $\mathrm{pH} 7$ & $\mathrm{pH} 8$ \\
\hline $\operatorname{AMP}(347.2)^{a)}$ & 3.9 & $<2$ & 6.4 & -0.022 & -0.154 & -0.645 & -0.948 & -0.995 & -1.999 & -2 \\
\hline CMP (323.2) & 4.5 & $<2$ & 6.6 & -0.004 & -0.031 & -0.240 & -0.760 & -0.969 & -1.997 & -2 \\
\hline GMP (363.2) & $2.4 ; 9.4$ & $<2$ & 6.7 & -0.334 & -0.799 & -0.975 & -0.997 & -1 & -2.004 & -2.038 \\
\hline UMP (324.1) & 9.5 & $<2$ & 6.6 & -1 & -1 & -1 & -1 & -1 & -2.003 & -2.031 \\
\hline Citrate & 3.13 & 4.76 & 6.40 & -0.069 & -0.438 & -1.030 & -1.660 & -2.223 & -2.797 & -2.975 \\
\hline Phosphate & 2.12 & 7.20 & 12.36 & -0.431 & -0.884 & -0.988 & -1.005 & -1.059 & -1.387 & -1.863 \\
\hline Formate & 3.75 & - & - & -0.017 & -0.151 & -0.640 & -0.947 & -0.994 & -1 & -1 \\
\hline
\end{tabular}

a) Molecular mass

$\mathrm{p} K_{\mathrm{a} 1}, \mathrm{p} K_{\mathrm{a} 2}, \mathrm{p} K_{\mathrm{a} 3}$ are the stepwise dissociation constants for each compound, except nucleotides. $\mathrm{p} K_{\mathrm{a} 1}$, dissociation constant for base moiety; $\mathrm{p} K_{\mathrm{a} 2}$ and $\mathrm{p} K_{\mathrm{a} 3}$, dissociation constants for primary phosphate group and secondary phosphate group, respectively. The data are from Handbook of Biochemistry and Molecular Biology, CRC Press, Boca Raton, FL 1975 , Vol. 1. 


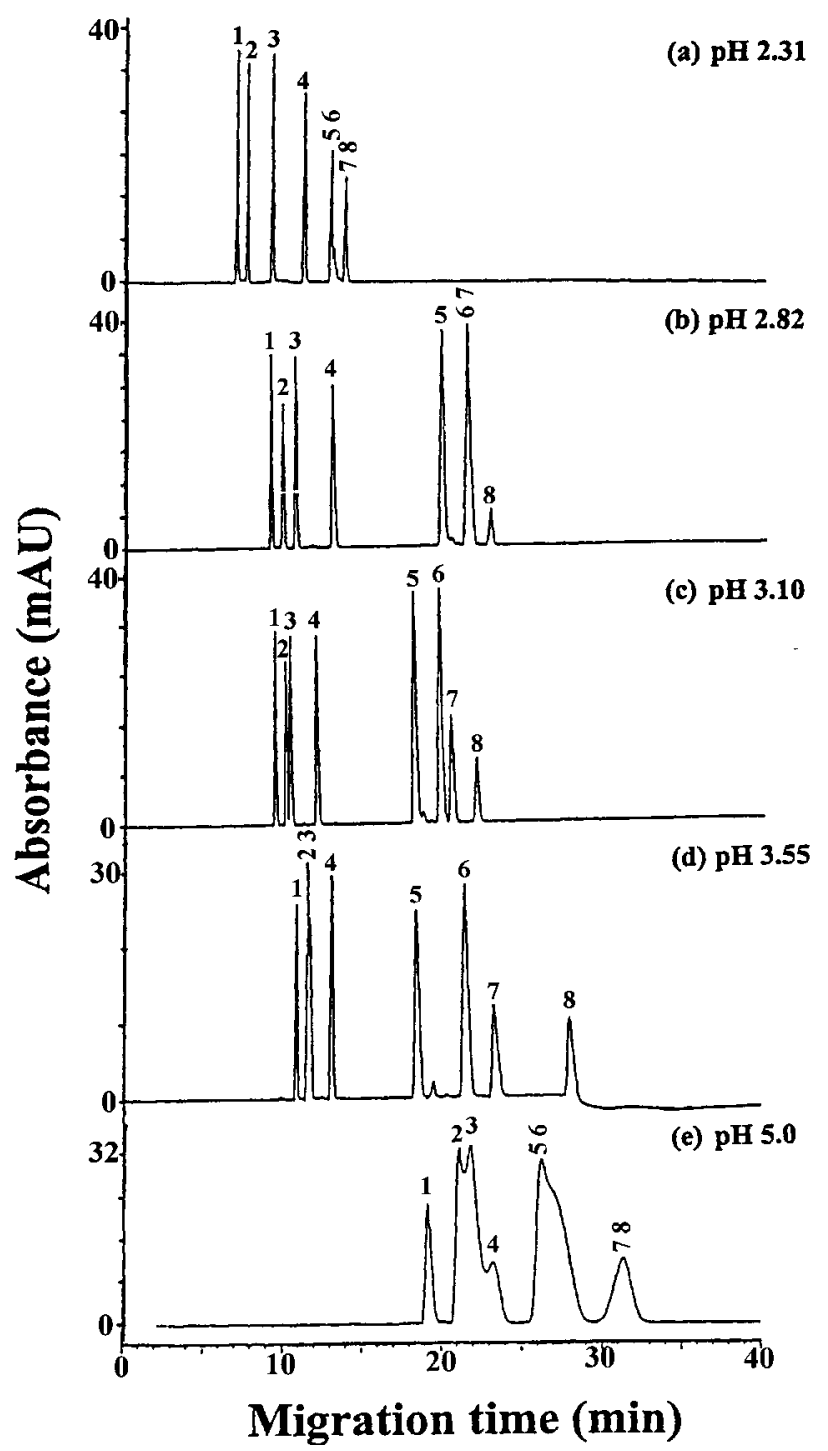

Figure 2. Electrophoretic separation of monophosphorylated nucleotides at different $\mathrm{pH}$ values. Column, [28]ane$\mathrm{N}_{6} \mathrm{O}_{2}$ bonded phase fused-silica capillary, $70 \mathrm{~cm}(50 \mathrm{~cm})$ $\times 75 \mu \mathrm{m}$ ID; applied voltage, $-15 \mathrm{kV}$; sample concentration, $0.05 \mathrm{mg} \cdot \mathrm{mL}^{-1}$; sample injection, electrokinetically $(-5 \mathrm{kV}, 10 \mathrm{~s})$; detection at $254 \mathrm{~nm}$; background electrolyte, phosphate buffer (30 mm): (a) $\mathrm{pH} 2.31$, (b) $\mathrm{pH} 2.82$, (c) $\mathrm{pH} 3.10$, (d) $\mathrm{pH} 3.55$, (e) $\mathrm{pH}$ 5.00. Peak identification: 1, 2'3'-cUMP; 2,. 5'-UMP; 3, 2'3'-cGMP; 4, 5'-GMP; 5, 2'3'-cAMP; 6, 5'-AMP; 7, 2'3'-cCMP; 8, 5'-CMP.

Table 2 shows the stability constants for anion binding by the polyammonium macrocycles in aqueous solution $[37,38]$. The ligands are not similar to ours, and heterogeneous systems are involved in this work. It is, however, worthy for reference. For cyclophane, a higher affinity was demonstrated for the nucleotide than the corresponding nucleoside and the base. In other words, phosphate moiety is the predominant active center for binding.
Table 2. Stability constants, log Ks for anion binding by the polyammonium macrocycles [24] $\mathrm{N}_{6},[32] \mathrm{N}_{8}$, $[27] \mathrm{N}_{6} \mathrm{O}_{3}$ in aqueous solution

\begin{tabular}{lllll}
\hline \multirow{2}{*}{ Anion } & \multicolumn{4}{c}{ Macrocyclic ligand } \\
\cline { 2 - 5 } & {$[24] \mathrm{N}_{6}{ }^{\mathrm{a})}$} & {$[32] \mathrm{N}_{8}^{\mathrm{a}}{ }^{2}$} & {$[27] \mathrm{N}_{6} \mathrm{O}_{3}{ }^{\mathrm{a})}$} & Cyclophane $^{\mathrm{b})}$ \\
\hline Citrate $^{3-}$ & 4.7 & 7.6 & 5.8 & - \\
AMP $^{2-}$ & 3.4 & 4.1 & 4.7 & 3.28 \\
$\mathrm{ADP}^{3-}$ & 6.5 & 7.5 & 7.7 & 4.15 \\
ATP $^{4-}$ & 8.9 & 8.5 & 9.1 & 4.57 \\
Adenine $_{\text {GMP2- }}$ & - & - & - & 1.70 \\
Adenosine $^{2}$ & - & - & - & 2.65 \\
Uridine & - & - & - & 1.60 \\
UMP2- & - & - & - & 1.00 \\
Cytosine & - & - & - & 2.90 \\
CMP2- & - & - & - & 1.23 \\
Guanosine & - & - & - & 2.97 \\
\hline
\end{tabular}

a) Data from [37]

b) Data from [38]

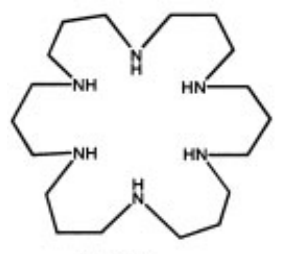

$[24] \mathrm{N}_{6}$

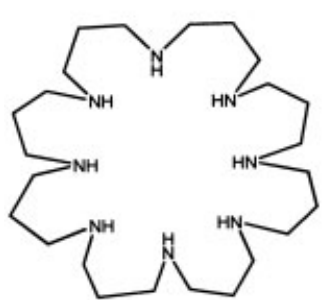

$[32] \mathrm{N}_{8}$

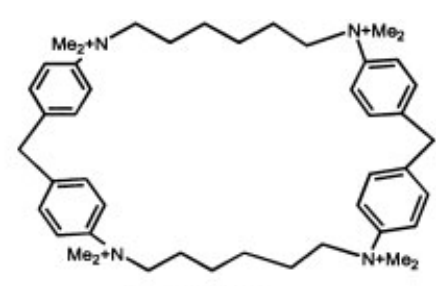

cyclophane

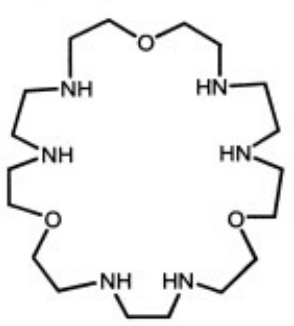

$[27] \mathrm{N}_{6} \mathrm{O}_{3}$
The data indicate that ligand-containing mix-donor atoms are more favorable for anion binding than those containing only the nitrogen donor atom. The advantage of the ligand chosen (Fig. 1) in our work is evident. Cyclic nucleotides have greater steric hindrance for complexation, therefore, they migrated faster than the corresponding analogues. Increasing the $\mathrm{pH}$ would result in a decrease of the protonated group. This causes a smaller EOF and a longer migration time for the analytes. Additionally, the separation efficiency for 5'-UMP and 2'3'cGMP was getting poorer. As the $\mathrm{pH}$ increased further to 5.0 , not only did more anions coelute, but also several broadened peaks were demonstrated. For these reasons, a $\mathrm{pH}$ of 3.10 was selected as the optimum condition for further work. 

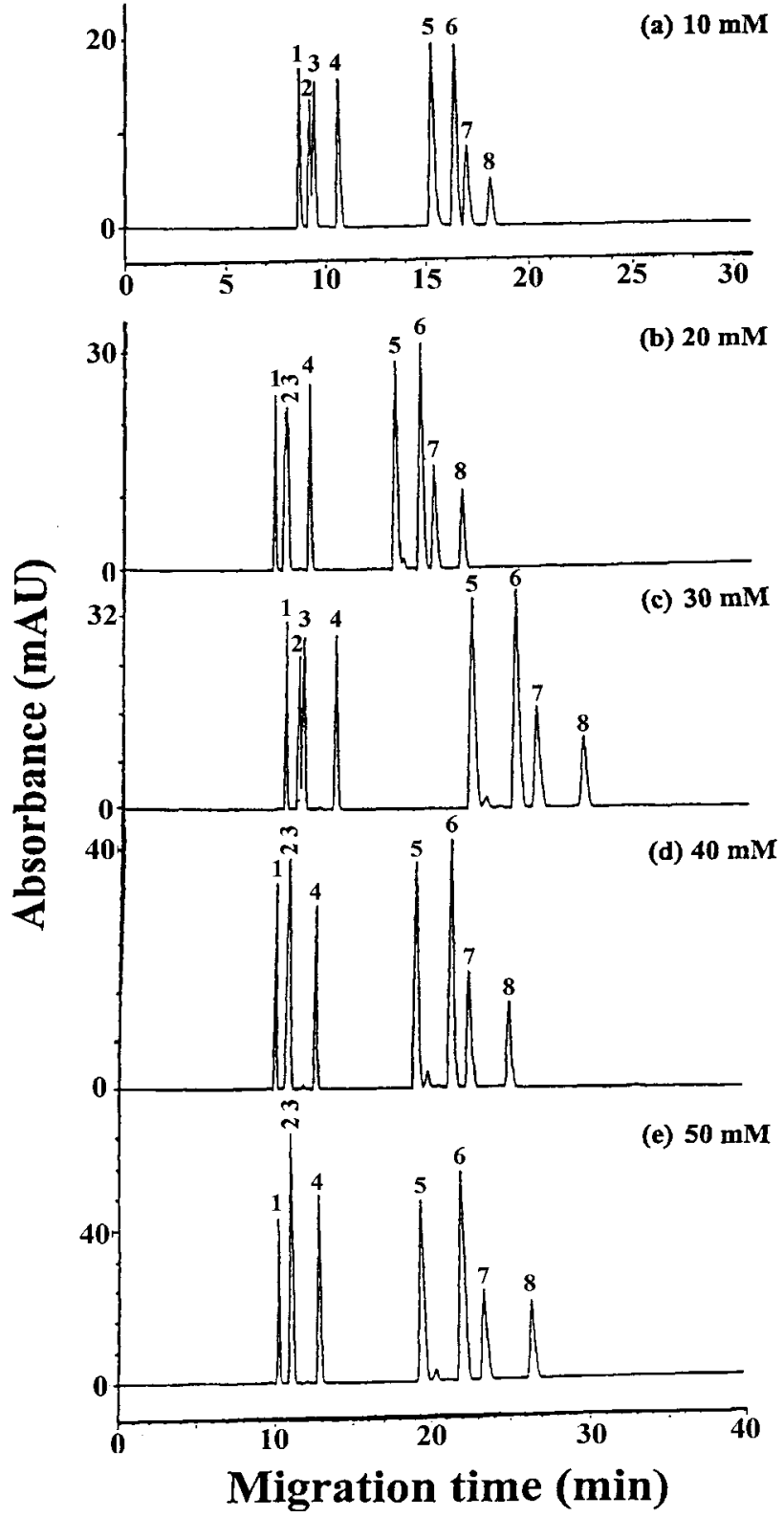

Figure 3. Electrophoretic separation of monophosphorylated nucleotides with different buffer concentrations. Conditions as in Fig. 2, except phosphate buffer ( $\mathrm{pH}$ 3.10): (a) $10 \mathrm{~mm}$, (b) $20 \mathrm{~mm}$, (c) $30 \mathrm{~mm}$, (d) $40 \mathrm{~mm}$, (e) $50 \mathrm{~mm}$.

\subsection{Effect of buffer concentration}

Electrophoresis buffers that influence the complexation reaction also affect the detectability and efficiency in CE. As the phosphate buffer concentration increased from 10 to $30 \mathrm{~mm}$, greater ionic strength resulted in a longer migration time for most analytes (Fig. 3). Moreover, inorganic phosphate is also a guest ion for the macrocyclic polyamine molecule. Therefore, faster migration was observed under the higher BGE concentration. This was particularly

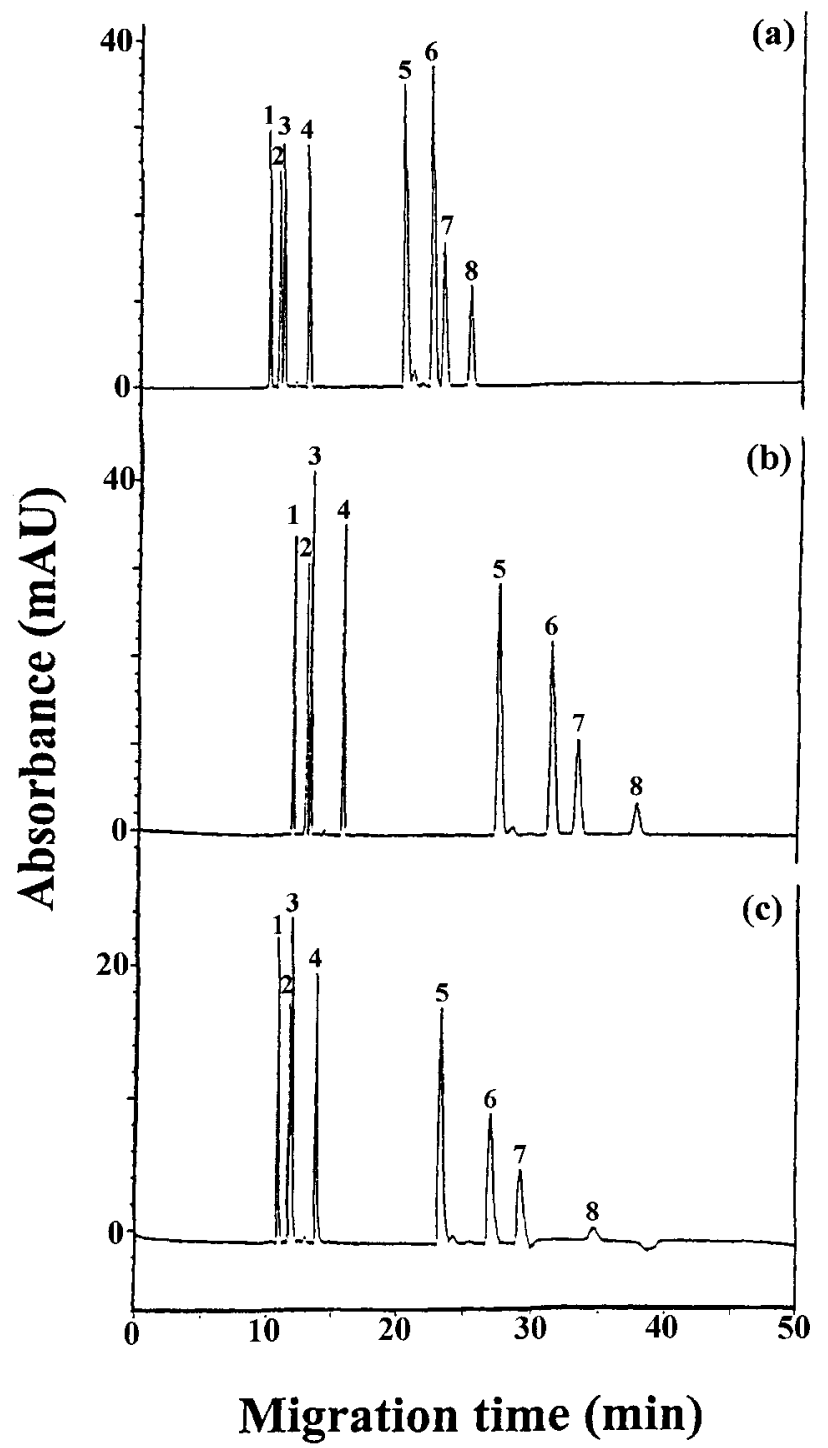

Figure 4. Electropherograms of monophosphorylated nucleotides with different background electrolytes. Conditions as in Fig. 2, except the background electrolyte (30 mm, pH 3.10): (a) phosphate buffer, (b) citrate buffer, (c) formate buffer.

evident for the higher affinity analyte. Meanwhile the detector response was greater as the BGE concentration increased. This might be due to the greater extent of the displacement reaction. Here, a buffer concentration of $30 \mathrm{~mm}$ was selected to maintain good peak shape and better resolution for all the analytes.

\subsection{Influence of applied voltage}

The effect of the applied voltage on the separation efficiency was also investigated. Increasing the applied voltage resulted in a faster migration of the analytes. How- 
Table 3. Separation efficiencies of the macrocyclic polyamine bonded phase under various background electrolytes ${ }^{\text {a) }}$

\begin{tabular}{|c|c|c|c|c|c|c|c|c|c|}
\hline \multirow{2}{*}{ Analyte } & \multicolumn{3}{|c|}{ Phosphate buffer } & \multicolumn{3}{|c|}{ Citrate buffer } & \multicolumn{3}{|c|}{ Formate buffer } \\
\hline & $t_{\mathrm{m}}(\mathrm{min})$ & $N\left(\mathrm{~m}^{-1}\right)^{\mathrm{b})}$ & $R s^{c)}$ & $t_{\mathrm{m}}(\min )$ & $N\left(\mathrm{~m}^{-1}\right)$ & Rs & $t_{\mathrm{m}}(\min )$ & $N\left(\mathrm{~m}^{-1}\right)$ & Rs \\
\hline 2'3'cyclic-UMP & 9.78 & 59000 & - & 11.86 & 107000 & - & 10.81 & 49000 & - \\
\hline 5'-UMP & 10.51 & 65000 & 4.80 & 12.87 & 115000 & 6.30 & 11.64 & 58000 & 3.79 \\
\hline 2'3'cyclic-GMP & 10.86 & 43000 & 1.17 & 13.21 & 117000 & 2.10 & 11.85 & 54000 & 0.88 \\
\hline 5'-GMP & 12.78 & 75000 & 9.98 & 15.74 & 96000 & 13.28 & 13.78 & 67000 & 8.05 \\
\hline 2'3'cyclic-AMP & 20.09 & 41000 & 28.00 & 27.35 & 53000 & 32.56 & 23.24 & 45000 & 25.64 \\
\hline 5'-AMP & 22.15 & 46000 & 7.36 & 31.28 & 53000 & 7.68 & 26.99 & 47000 & 6.18 \\
\hline 2'3'cyclic-CMP & 23.04 & 43000 & 3.02 & 33.23 & 47000 & 3.25 & 29.24 & 42000 & 3.06 \\
\hline 5'-CMP & 25.04 & 54000 & 6.60 & 37.72 & 46000 & 6.84 & 34.61 & 50000 & 6.54 \\
\hline
\end{tabular}

a) Column, [28]ane- $\mathrm{N}_{6} \mathrm{O}_{2}$ bonded phase fused-silica capillary; $70 \mathrm{~cm}(50 \mathrm{~cm}) \times 75 \mu \mathrm{m}$ ID; background electrolyte, phosphate buffer (30 mM, pH 3.10); applied voltage, $-15 \mathrm{kV}$; sample concentration, $0.05 \mathrm{mg} \cdot \mathrm{mL}^{-1}$; sample injection, electrokinetically $(-5 \mathrm{kV}, 10 \mathrm{~s})$; detection at $254 \mathrm{~nm}$

b) Theoretical plate, $N=5.54\left(t_{\mathrm{m}} / W_{1 / 2}\right)$

c) Resolution, $R s=2\left(t_{2}-t_{1}\right) /\left(w_{1}+w_{2}\right)$

ever, the resolution of 5'-UMP and 2'3'-cGMP deteriorated by increasing the voltage to $-20 \mathrm{kV}$. Therefore, $-15 \mathrm{kV}$ was selected for further work.

\subsection{Effect of buffer composition}

For anion coordination, the degree of interaction with the stationary phase might be affected by the presence of competing ions. In addition to the phosphate, two alternating BGEs, citrate, and formate buffer, were also applied to the separation of these nucleotides. The electropherograms of these separations are shown in Fig. 4. The separation efficiencies with these buffers are summarized in Table 3. A greater number of theoretical plates with an average of $79250 \mathrm{~m}^{-1}$ and better resolution for most analytes was demonstrated with citrate buffer, however, a broader peak was observed for the slowing migration ion than that in the phosphate buffer. A longer migration time was needed with the citrate buffer. A lower complexation affinity of citrate than phosphate ion toward the bonded phase might be the reason. For the peak resolution of 5'-UMP and 2'3'cyclic-GMP, and peak intensity of all analytes (Fig. 4), formate, the most simple organic acid, seems not so good compared with phosphate and citrate buffer. This is likely due to less hydrophobic forces and weaker electrostatic forces between formate and the bonded phase. Based on the above considerations, the affinity for the anion coordination toward the bonded phase decreases in the order: phosphate $>$ citrate $>$ formate. This conclusion was consistent with the order of effective charge at $\mathrm{pH} 3$ shown in Table 1.

To account for the effect of the bonded phase on the analytes, the separation behavior was also compared with that of the bare fused-silica capillary. Using experimental conditions similar to the bonded phase, only two nonbaseline-resolved peaks (at 6.62 and $7.31 \mathrm{~min}$ ) for these eight analytes were indicated. Evidently, not only electrophoretic mobility but also anion coordination should be involved in our column separation. Additionally, the protonated bonded phases have ammonium functionalities, anion-exchange might have some contribution to the separation. In view of this effect, the strengths of various analytes interacting with the bonded group should be proportional to the charge of the analytes, related to the size of the hydrated ions as well as the molecular structure. Some deviation from this behavior was indicated. In other words, anion coordination seems a more important role for the separation.

\subsection{Stability of the column}

Using the bonded phase $(70 \mathrm{~cm} \times 75 \mathrm{~mm} \mathrm{ID})$ with electrokinetic injection $(-5 \mathrm{kV}, 10 \mathrm{~s})$, the linearity of the response for the established method is summarized in Table 4. Detection limit defined as three times the signal-tonoise ratio was lower than $0.2 \mathrm{mgL}^{-1}$ for most analytes except 2'3'-cCMP and 5'-CMP. To assess the longterm stability of the column, the results from six consecutive injections were measured after the column had been used for longer than three months, namely more than 1000 injections had taken place (Table 5). The results were also compared with those of the column being just prepared. Here, we must mention that the initial EOF was $-1.83 \times 10^{-4} \mathrm{~cm}^{2} \mathrm{~V}^{-1} \mathrm{~s}^{-1}$, while after use for three months, the EOF had deteriorated to $-7.59 \times$ $10^{-5} \mathrm{~cm}^{2} \mathrm{~V}^{-1} \mathrm{~s}^{-1}$, but the relative standard deviation (RSD\%) was within $3.5 \%$ for six consecutive injections, even after 
Table 4. Quantitation of nucleoside monophosphates with macrocyclic polyamine bonded phase by $\mathrm{CE}^{\mathrm{a})}$

\begin{tabular}{|c|c|c|c|c|}
\hline \multirow[t]{2}{*}{ Nucleotide } & \multicolumn{3}{|c|}{ Linear equation $\left(x\right.$, peak area $/ \mu \mathrm{Vs} ; y$, concentration $\left./ \mathrm{mg} \cdot \mathrm{L}^{-1}\right)$} & \multirow{2}{*}{$\begin{array}{l}\text { Detection limit }{ }^{\mathrm{b})} \\
\mathrm{mg} \cdot \mathrm{L}^{-1}(\mu \mathrm{m})\end{array}$} \\
\hline & Slope & Intercept & $r^{2}$ & \\
\hline 2'3'cyclic-UMP & $2.12 \times 10^{6}$ & $4.48 \times 10^{4}$ & 0.9911 & $0.09(0.27)$ \\
\hline 5'-UMP & $2.92 \times 10^{6}$ & $3.38 \times 10^{4}$ & 0.9981 & $0.13(0.35)$ \\
\hline 2'3'cyclic-GMP & $2.66 \times 10^{6}$ & $5.77 \times 10^{4}$ & 0.9948 & $0.09(0.25)$ \\
\hline 5'-GMP & $4.51 \times 10^{6}$ & $5.12 \times 10^{4}$ & 0.9960 & $0.14(0.34)$ \\
\hline 2'3'cyclic-AMP & $6.57 \times 10^{6}$ & $1.65 \times 10^{5}$ & 0.9864 & $0.12(0.34)$ \\
\hline 5'-AMP & $1.08 \times 10^{7}$ & $1.39 \times 10^{5}$ & 0.9936 & $0.19(0.55)$ \\
\hline 2'3'cyclic-CMP & $3.77 \times 10^{6}$ & $9.06 \times 10^{4}$ & 0.9887 & $0.26(0.80)$ \\
\hline 5'-CMP & $2.93 \times 10^{6}$ & $2.53 \times 10^{4}$ & 0.9906 & $0.41(1.12)$ \\
\hline
\end{tabular}

a) Conditions as in Table 3, except sample concentration range, $2.5 \sim 50 \mathrm{mg} \cdot \mathrm{L}^{-1}$

b) Three times of signal-to-noise ratio

Table 5. Migration time repeatability in the CE separation of nucleoside monophosphates ${ }^{\text {a) }}$

\begin{tabular}{lllll}
\hline Nucleotide & Migration time $(\mathrm{min})$ & $\mu_{\mathrm{ep}}\left(\mathrm{cm}^{2} \mathrm{~V}^{-1} \mathrm{~s}^{-1}\right)$ & $\mathrm{SD}$ & $\mathrm{RSD}(\%)$ \\
\hline 2'3'cyclic-UMP & $12.18(9.56)^{\mathrm{c})}$ & $-2.43 \times 10^{-4}\left(-2.45 \times 10^{-4}\right)^{\mathrm{c})}$ & $0.28(0.13)^{\mathrm{c})}$ & $\left.2.31(1.38)^{\mathrm{c}}\right)$ \\
5'-UMP & $13.32(10.22)$ & $-2.16 \times 10^{-4}\left(-2.19 \times 10^{-4}\right)$ & $0.30(0.15)$ & $2.25(1.48)$ \\
2'3'cyclic-GMP & $13.68(10.53)$ & $-2.08 \times 10^{-4}\left(-2.07 \times 10^{-4}\right)$ & $0.32(0.14)$ & $2.38(1.32)$ \\
5'-GMP & $16.61(12.16)$ & $-1.58 \times 10^{-4}\left(-1.58 \times 10^{-4}\right)$ & $0.43(0.18)$ & $2.62(1.49)$ \\
2'3'cyclic-AMP & $30.91(18.37)$ & $-5.01 \times 10^{-5}\left(-5.00 \times 10^{-5}\right)$ & $1.06(0.31)$ & $3.43(1.67)$ \\
5'-AMP & $36.48(20.04)$ & $-3.11 \times 10^{-5}\left(-3.20 \times 10^{-5}\right)$ & $1.23(0.40)$ & $3.37(2.01)$ \\
2'3'cyclic-CMP & $39.11(20.91)$ & $-2.35 \times 10^{-5}\left(-2.40 \times 10^{-5}\right)$ & $1.29(0.41)$ & $3.30(1.96)$ \\
5'-CMP & $45.62(22.52)$ & $-9.30 \times 10^{-6}\left(-1.10 \times 10^{-5}\right)$ & $1.55(0.50)$ & $3.39(2.22)$ \\
\hline
\end{tabular}

a) Conditions as in Table 3

b) Six consecutive injections after the column was long-term used for longer than 3 months (injections more than 1000); $\mu_{\text {eof }}=-7.59 \times 10^{-5} \mathrm{~cm}^{2} \mathrm{~V}^{-1} \mathrm{~s}^{-1}$

c) Six consecutive injections after the column was freshly prepared; $\mu_{\text {eof }}=-1.83 \times 10^{-4} \mathrm{~cm}^{2} \mathrm{~V}^{-1} \mathrm{~s}^{-1}$

more than a thousand injections. There was no significant difference between the $\mu_{\mathrm{ep}}$ calculated for both conditions (Table 5).

\subsection{Analytical application}

The potential of the method for the analysis of nucleotides in complex matrices was also investigated. Three kinds of mushrooms obtained from the supermarket were heated in a microwave oven for $20 \mathrm{~s}$ following immersion in pure water $(20 \mathrm{~min})$. The electropherograms for the aqueous extracts are shown in Fig. 5. The amount of 5'-AMP is highest, 5'-GMP is next, followed by 5'-UMP, and 5'CMP in decreasing order. We also found that the amounts of these components were dependent on the mode of extraction. All of them were found in the samples treated by immersion in pure water for $20 \mathrm{~min}$, heating in the microwave for $20 \mathrm{~s}$ and cooking in boiling water for
15 min, but only 5'-UMP was found in the sample treated in pure water at ambient temperature for 60 min (Fig. 6). Among them, the sample treated in boiling water provided the highest amount of nucleotides in the aqueous extracts (Fig. 7).

\section{Concluding remarks}

This study demonstrates the recognition of macrocyclic polyamine bonded phase toward nucleoside monophosphates by CE. With phosphate buffer $(30 \mathrm{~mm}, \mathrm{pH} 3.10)$ and an applied voltage of $-15 \mathrm{kV}$, the separation of eight nucleoside monophosphates, including the cyclic corresponding analogues could be separated with the theoretical plate of $53250 \mathrm{~m}^{-1}$. No modifier was needed for the EOF reversal. Therefore, rather a low detection limit could be obtained. The results described here not only show how anion coordination can be introduced into the 


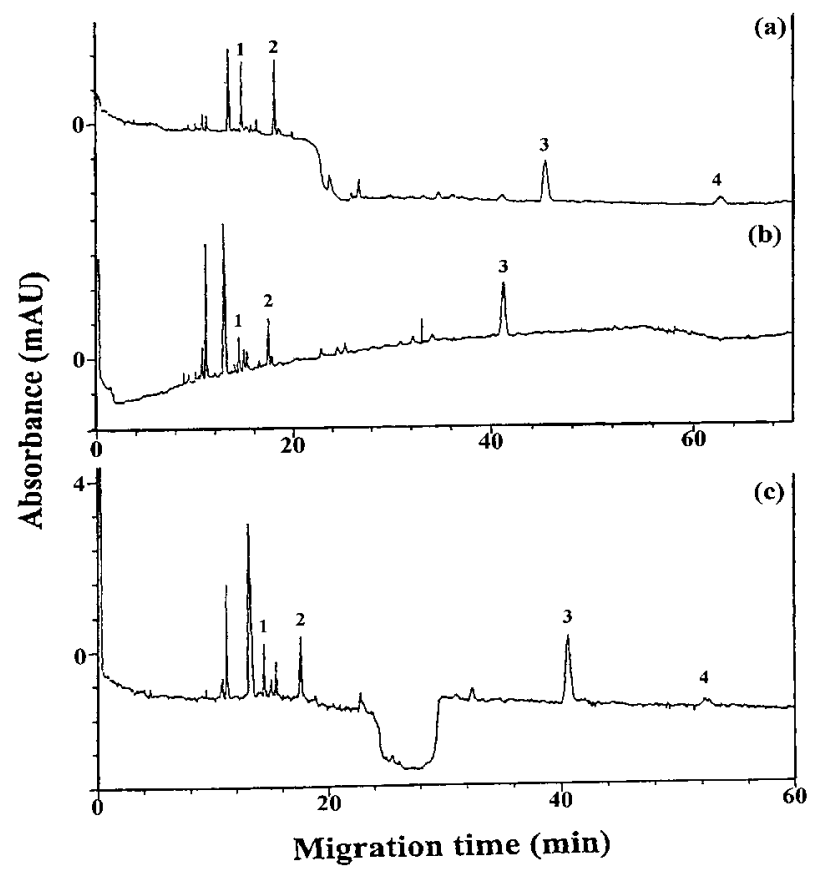

Figure 5. Electropherograms of nucleotide in aqueous extracts of mushrooms from different species. Column: Conditions as in Fig. 2 except background electrolyte, phosphate buffer (30 mM, pH 3.10). Sample treatment: immersion of the sample in pure water $(20 \mathrm{~min})$, then heating in the microwave oven (20 s). Peak identification: 1, 5'-UMP; 2, 5'-GMP; 3, 5'-AMP; 4, 5'-CMP.

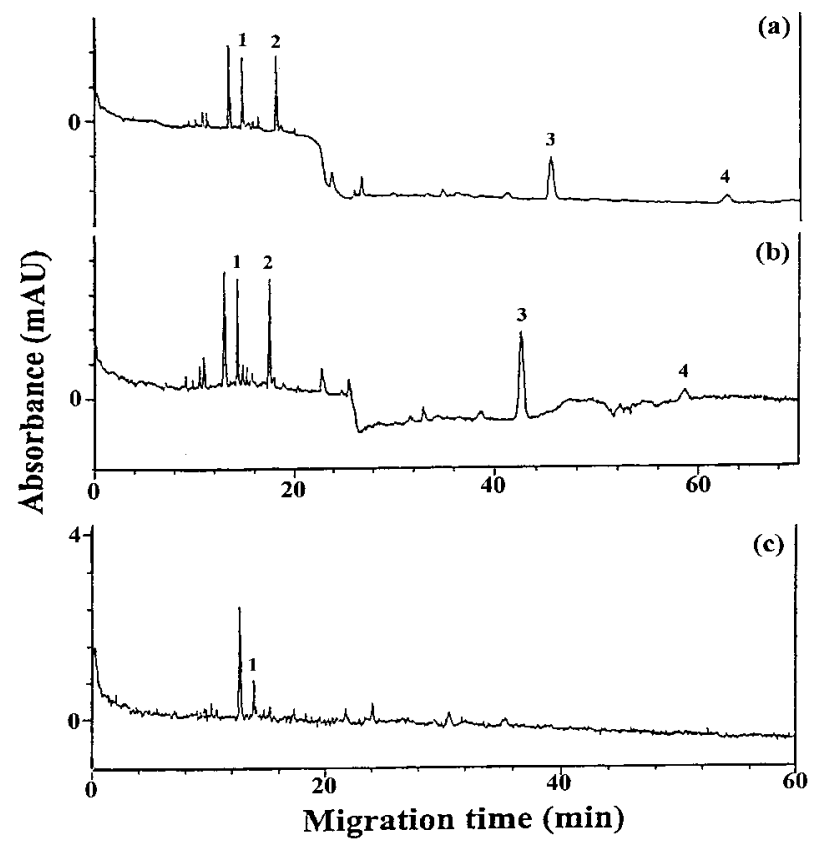

Figure 6. Electropherograms of monophosphorylated nucleotides in aqueous extracts of mushrooms from different methods of extraction. Conditions as in Fig. 5 except method of extraction: (a) immersion in pure water (20 min), then heating in the microwave oven (20 s); (b) cooking in boiling water (15 min); (c) immersion in pure water at ambient temperature $(60 \mathrm{~min})$.

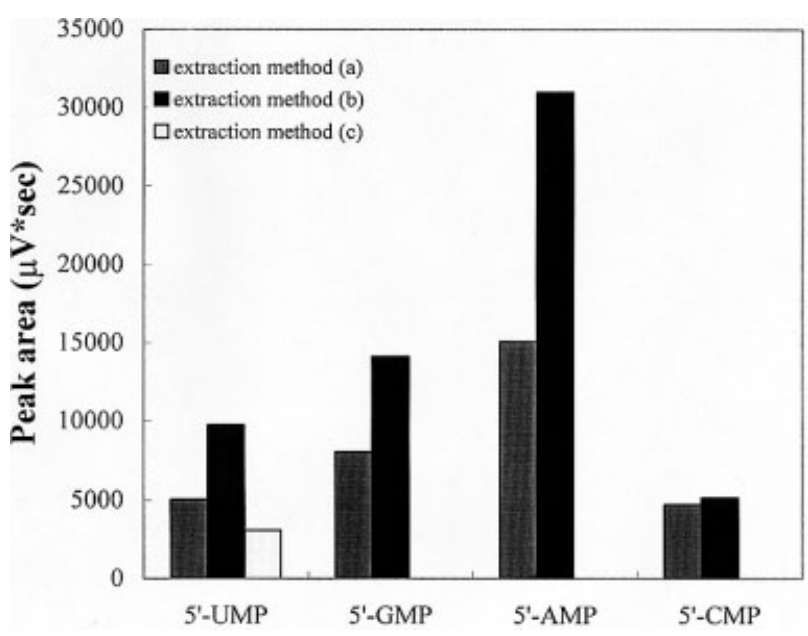

Figure 7. Amount of the monophosphorylated nucleotide in aqueous extracts of mushrooms from different methods of extraction. Conditions as in Fig. 6.

bonded phase for the recognition of nucleotides but also indicate that the prepared column was highly stable for long-term use (more than three months, namely more than thousand injections). The satisfactory results for the analysis of nucleotides in mushroom also indicate that the bonded phase could be employed for the selective binding of nucleotides in other complex matrix samples that are of chemical and biological interest.

The authors thank the National Science Council of Taiwan for financial support.

Received September 7, 2001

\section{References}

[1] Hosseini, M. W., Lehn, J. M., Mertes, M. P., Helv. Chim. Acta 1983, 66, 2454-2466.

[2] Schneider, H. J., Durr, H. (Eds.), Frontiers in Supramolecular Organic Chemistry and Photochemistry, VCH, Weinheim, Germany 1991.

[3] Schneider, H. J., Yatsimirsky, A. K., Principles and Methods in Supramolecular Chemistry, John Wiley \& Sons, New York, NY, USA 2000.

[4] Uesugi, T., Sano, K., Uesawa, Y., Ikegami, Y., Mohri, K., J. Chromatogr. B 1997, 703, 63-74.

[5] Zakaria, M., Brown, P. R., J. Chromatogr. 1981, 226, 267290.

[6] Simek, P., Jegorov, A., Dusbabek, F., J. Chromatogr. A 1994, 679, 195-200.

[7] Zhao, J., Todd, B., Fleet, G. H., J. Chromatogr. A 1994, 673, 167-171.

[8] Fischer, J. H., LC-GC Int. 1995, 8, 254-264.

[9] Krauss, G. J., Pissarek, M., Blasig, I., J. High Resol. Chromatogr. 1997, 20, 693-696.

[10] Djordjevic, N. M., Houdiere, F., Fowler, P., Natt, F., Anal. Chem. 1998, 70, 1921-1925. 
[11] Sessler, J. L., Gale, P. A., Genge, J. W., Chem. Eur. J. 1998 4, 1095-1099.

[12] Huang, X., Shear, J. B., Zare, R. N., Anal. Chem. 1990, 62, 2049-2051.

[13] Huang, M., Liu, S., Murray, B. K., Lee, M. L., Anal. Biochem. 1992, 207, 231-235.

[14] Shao, X., O’Neill, K., Zhao, Z., Anderson, S., Malik, A., Lee, M. L., J. Chromatogr. A 1994, 680, 463-468.

[15] Tadey, T., Purdy, W. C., J. Chromatogr. B 1994, 657, 365372.

[16] O'Neill, K., Shao, X., Zhao, Z., Malik, A., Lee, M. L., Anal. Biochem. 1994, 222, 185-189.

[17] Zhao, Z., Wahl, J. H., Udseth, H. R., Hofsadler, S. A., Fuciarelli, A. F., Smith, R. D., Electrophoresis 1995, 16, 389-395.

[18] Hayes, J. D., Malik, A., J. Chromatogr. B 1997, 695, 3-13.

[19] Lin, H., Xu, D. K., Chen, H. Y., J. Chromatogr. A 1997, 760, 227-233.

[20] Wang, T., Li, S. F. Y., J. Chromatogr. A 1997, 779, 215-225.

[21] Geldart, S. E., Brown, P. R., J. Chromatogr. A 1997, 792, 67-73.

[22] Shao, X., Shen,Y., Lee, M. L., O'Neill, K., J. Chromatogr. A 1998, 809, 173-179.

[23] Kawamura, K., J. Chromatogr. A 1998, 802, 167-177.

[24] Elisabeth, P., Yoshioka, M., Sasaki, T., Senda, M., J. Chromatogr. A 1998, 806, 199-207.

[25] Cahours, X., Morin, P., Dreux, M., Chromatographia 1998, $48,739-744$
[26] Shao, X., Shen, Y., O’Neill, K., Lee, M. L., Chromatographia 1999, 49, 299-305.

[27] Cahours, X., Morin, P., Dreux, M., Chromatographia 1999, 49, 379-384.

[28] Shao, X., Shen, Y., O'Neill, K., Lee, M. L., J. Chromatogr. A 1999, 830, 415-422.

[29] Fu, C., Song, L., Fang, Y., Anal. Chim. Acta 1999, 399, 259-263.

[30] Cahours, X., Morin, Ph., Dreux, M., Chromatographia 2000, 51, 586-590.

[31] McKeown, A. P., Shaw, P. N., Barrett, D. A., Electrophoresis 2001, 22, 1119-1125.

[32] Sykora, D., Svec, F., Frechet, J. M.J., J. Chromatogr. A 1999, 852, 297-304.

[33] Hsu, J. C., Chen, W. H., Liu, C. Y., Analyst 1997, 122, 13931398.

[34] Liu, C. Y., Chen, W. H., J. Chromatogr. A 1998, 815, 251263.

[35] Chen, W. H., Liu, C. Y., J. Chromatogr. A 1999, 848, 401416.

[36] Chen, W. H., Lin, S. Y., Liu, C. Y., Anal. Chim. Acta 2000, 410, 25-35.

[37] Dietrich, B., Hosseini, N. W., Lehn, J. M., Sessions, R. B., J. Am. Chem. Soc. 1981, 103, 1282-1283.

[38] Schneider, H. J., Blatter, T., Palm, B., Pfingstag, U., Rudigeer, V., Theism, I., J. Am. Chem. Soc. 1992, 114, 7704-7708. 